\title{
Mobile test stand for evaluation of electric power plants for unmanned aircraft
}

\author{
Vladimir Serbezov ${ }^{1, *}$, Stamen Dimitrov ${ }^{2}$, and Konstantin Rangelov ${ }^{1}$ \\ ${ }^{1}$ Dronamics Ltd., 4 Iskar St., 1000 Sofia, Bulgaria \\ ${ }^{2}$ Department of Aeronautics, Technical University - Sofia, 8 Kl. Ohridski Blvd., 1000 Sofia, Bulgaria
}

\begin{abstract}
The absence of accurate performance data is a common problem with most civilian unmanned aerial vehicle (UAV) power plant producers. The reasons for this are the small size of most of the manufacturers and the high price of precise wind tunnel testing and computer simulations. To overcome this problem at Dronamics Ltd., with support from the Department of Aeronautics of TU-Sofia, a mobile test stand for evaluation of electric power plants for unmanned aircraft was developed. The stand may be used statically, or may be installed on the roof of an automobile. The measurement system of the stand is based on popular hardware that is used in radio controlled models and in general automation. The verification of the measurement system is performed by comparing static test results with data published by the manufacturer of the tested electric motor. Tests were carried out with 2 different types of propellers and the results were compared with published results for common propellers as well as with results of theoretical studies. The results are satisfactory for practical applications. The use of this type of test stands can be a cheap and effective alternative for research and development start-up companies like Dronamics.
\end{abstract}

\section{Introduction}

The absence of accurate performance data is a common problem with most civilian UAV propeller and engine producers. The reasons for this are the small size of most manufacturers and the high price of precise wind tunnel testing and computer simulations. In recent years there has been some academic effort to cover this gap. A good example is the survey performed by Brandt and Selig [1]. They tested different small propellers (up to 11" diameter) in a wind tunnel. In addition, there were some attempts by UAV enthusiasts to overcome this issue by deriving empiric thrust equation for a propeller with a given diameter and pitch [2]. The latter may serve as a rough approximation for preliminary design, but they do not account for important factors such as widely varying Reynolds number and propeller geometry.

Research in the field of UAV propeller performance is carried out also in Bulgaria [3, 4]. It yielded promising results but it is focused mostly on multi copter rotors and it is not applicable for fixed wing UAVs with relatively large propellers with diameters of up to 30 " (762 mm).

To overcome this problem in the interest of Dronamics experimental prototypes, with the support of the Department of Aeronautics of Technical University Sofia a test stand for testing propeller/electric motor powerplants for UAVs was constructed. In order to make testing at high propeller advance ratios possible it was decided to mount the test stand on the roof of a passenger automobile. Partially, this decision was motivated by tests carried at NASA Armstrong Flight
Research Center [5]. Another feature of the project was that its target was to solve a practical problem at affordable cost. For this reason, the measurement and data acquisition systems of the test bench were based on popular hardware that is used in radio controlled models and in general automation.

\section{Test stand description}

The general arrangement of the test stand (set for static test on the ground) is shown in Fig. 1.

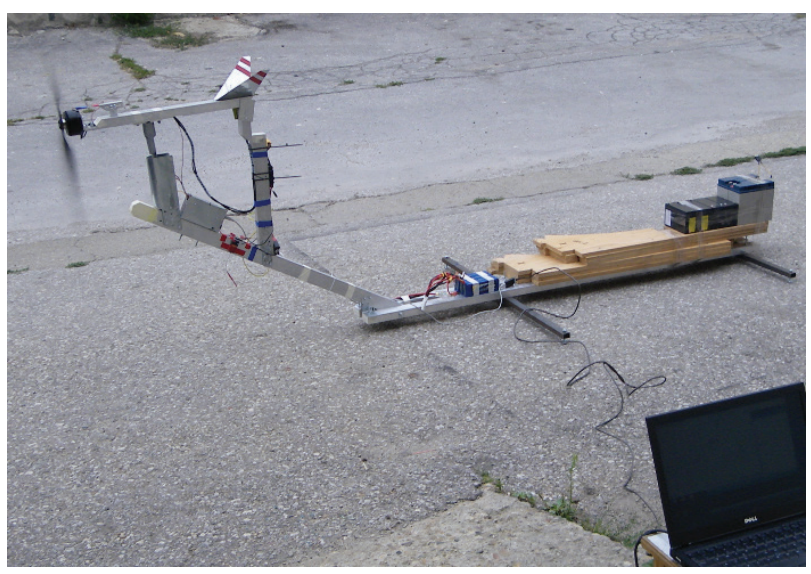

Fig. 1. Static installation of the test stand.

It was assumed that thrust measurement is most important and the shaft power can be estimated from the electrical power of the engine, given its efficiency is

\footnotetext{
*Corresponding author: vserbezov@,dronamics.com
} 
relatively constant. This allowed significant simplification of the stand structure and use of strain gauges placed on a bending loaded beam.

An Arduino Uno board, connected by a serial port with a laptop, was used as the data acquisition system. The Arduino board allowed for stable operation with a sample rate of approximately 2 samples per second, which was judged to be satisfactory for the stand needs. The Arduino board was placed in a box right behind the thrust beam of the stand. The sensors used are listed in Table 1.

Table 1. List of sensors.

\begin{tabular}{|c|c|c|}
\hline $\begin{array}{c}\text { Sensed } \\
\text { quantity }\end{array}$ & Sensor & Data acquisition \\
\hline Thrust & $\begin{array}{c}\text { Sparkfun HX711 load } \\
\text { cell amplifier }\end{array}$ & $\begin{array}{c}\text { Arduino, } \\
\text { digital input }\end{array}$ \\
\hline Rotational speed & $\begin{array}{c}\text { US1881 latch hall } \\
\text { sensor }\end{array}$ & $\begin{array}{c}\text { Arduino, } \\
\text { digital input }\end{array}$ \\
\hline $\begin{array}{c}\text { Ambient } \\
\text { pressure }\end{array}$ & $\begin{array}{c}\text { BMP-183 Barometric } \\
\text { Pressure and Altitude } \\
\text { Sensor }\end{array}$ & $\begin{array}{c}\text { Arduino, } \\
\text { digital input }\end{array}$ \\
\hline $\begin{array}{c}\text { Ambient } \\
\text { Temperature }\end{array}$ & BMP-183 \\
\hline $\begin{array}{c}\text { Engine input } \\
\text { voltage }\end{array}$ & $\begin{array}{c}\text { 60V to 5V voltage } \\
\text { splitter }\end{array}$ & $\begin{array}{c}\text { Arduino, } \\
\text { digital input }\end{array}$ \\
\hline $\begin{array}{c}\text { Engine input } \\
\text { current }\end{array}$ & $\begin{array}{c}\text { ACS709 hall sensor input } \\
\text { up to 75A }\end{array}$ & $\begin{array}{c}\text { Arduino, } \\
\text { analogue input }\end{array}$ \\
\hline Airspeed & $\begin{array}{c}\text { HD350 pitot tube } \\
\text { anemometer }\end{array}$ & $\begin{array}{c}\text { Serial connection } \\
\text { with the computer }\end{array}$ \\
\hline Ground speed & $\begin{array}{c}\text { Garmin GPSMAP } \\
60 \mathrm{CSx}\end{array}$ & $\begin{array}{c}\text { Internal memory } \\
\text { storage }\end{array}$ \\
\hline
\end{tabular}

\subsection{Propeller thrust measurement}

Some designs of the load cell were evaluated in ANSYS. Finally, a standard I beam was chosen. The boundary conditions and results of the strain analysis are shown in Figures 2 and 3. The $350 \mathrm{Ohm}$ strain gauges, connected in half-bridge, have a resistance change of $0,3566 \mathrm{Ohm}$ at $100 \mathrm{~N}$ load, which results in $1,885 \mathrm{mV}$ output at $3,7 \mathrm{~V}$ bridge input voltage. The output is sensed by a Sparkfun HX711 load cell amplifier.

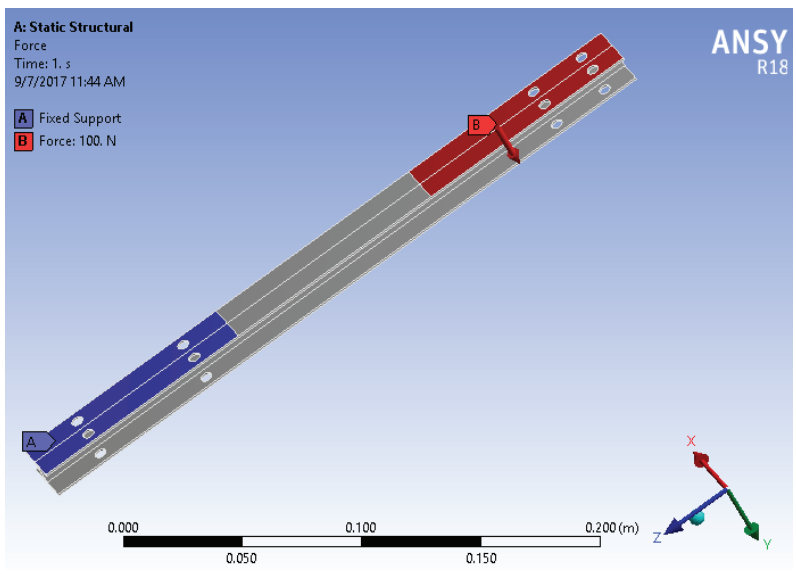

Fig. 2. Boundary conditions and loading applied on Thrust beam in ANSYS.
The calibration of the load cell was performed on the test stand, by loading it and measuring the load with a general purposes electronic scale with $10 \mathrm{~g}$ accuracy. Two cycles of step loading/unloading from 0 to $15 \mathrm{~kg}$ were performed. The results are shown in Fig. 4. A hysteresis of $0,3 \mathrm{~kg}$ was observed at maximum load which was assumed to be satisfactory. Also, there was a slight nonlinearity due to the imprecise placement of the gauges on the beam, but it was corrected through the use of a second order polynomial correction performed in the Arduino.

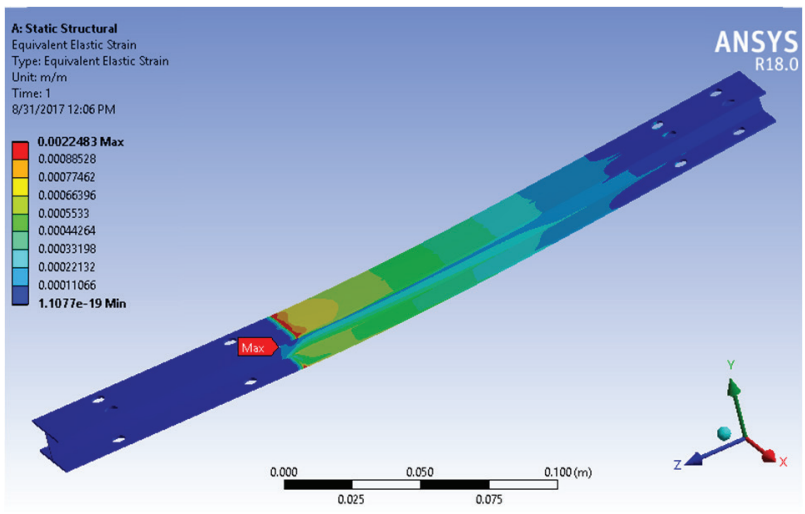

Fig. 3. Strain analysis of the thrust beam in ANSYS.

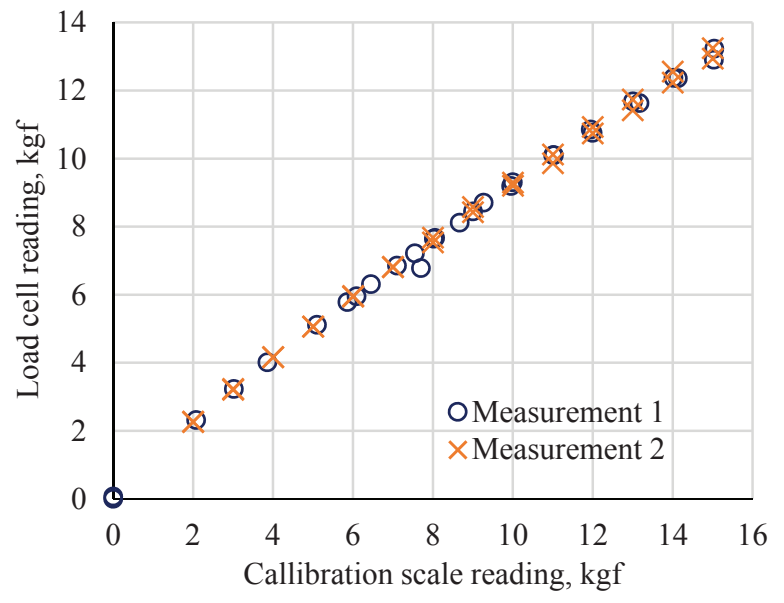

Fig. 4. Thrust measurement system calibration results.

\subsection{Engine speed measurement}

The T-motor U11KV90 DC engine is an 'outrunner' type, e.g. it has a rotating case with permanent magnets, placed on its inner surface. This configuration results in strong magnetic field around the engine, allowing for the use of a latch hall sensor placed over the engine rotor, connected to an interrupt digital input of the Arduino board. The rotational speed was calculated by counting the number of interrupts per data sample interval. The System was tested and approbated with the help of a manual laser RPM reader.

\subsection{Electric signals measurement}

The voltage and current were measured at the input of the engine speed controller. Voltage up to $60 \mathrm{~V}$ DC was 
sensed through a voltage splitter at a $5 \mathrm{~V}$ analogue input of the Arduino board with 10-bit resolution. The ACS 709 current sensor was connected to Arduino in a similar way. It was connected at the minus input of the engine speed controller.

\subsection{Ambient conditions and airspeed measurement}

The ambient pressure and temperature were measured by a .BMP-183 barometric pressure sensor, placed inside the Arduino box. A disadvantage of this position was that the temperature reading was influenced by the heat from the sun and propeller airstream cooling. For this reason, an additional temperature reference was needed for the after calculations.

The airspeed, when the stand was placed on the roof of an automobile, was measured by a HD350 Pitot tube anemometer, connected through a USB connection to the laptop. The data logger programs of the Arduino and the anemometer used the computer clock, allowing for an easy merger of the data. The Pitot tube was mounted approximately $0,5 \mathrm{~m}$ off the right side of the car (visible on Fig. 5). It was assumed that this position will be unaffected by the car boundary layer and the propeller stream.

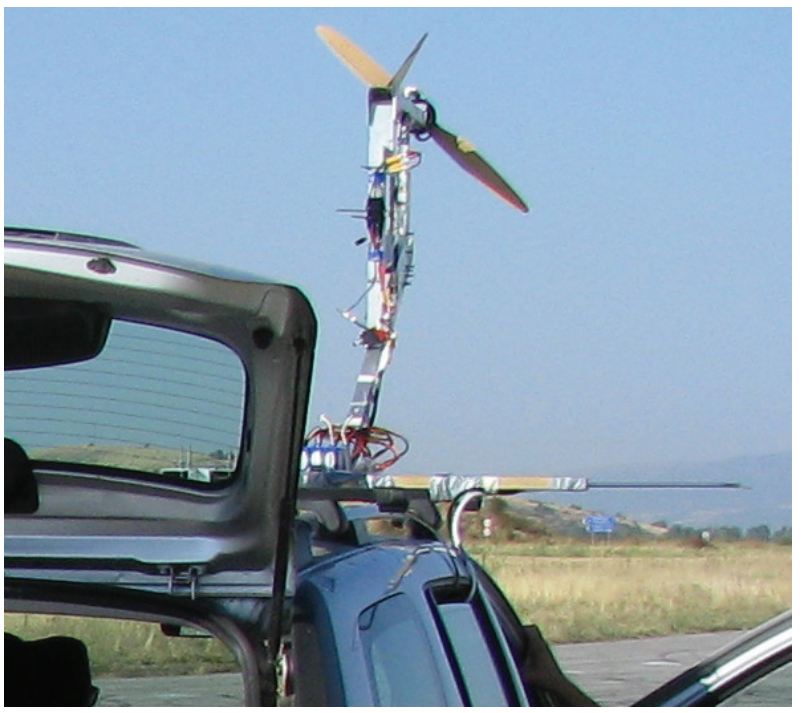

Fig. 5. The test stand mounted for runway tests.

For additional ground speed reference an Garmin GPSMAP 60CSx handheld system was mounted inside the automobile. The GPS system stored the data in its internal memory, requiring preliminary synchronization of the GPS and the data logging computer.

\section{Static testing}

The static tests were performed with T-motor U11KV90 DC motor with T-motor G29 $\times 9,5$ propeller, which is optimised for multirotor UAVs. The aim was to test the data acquisition system and to approbate it using existing performance data from the motor and propeller manufacturer [6]. An additional task was to test the endurance of the batteries that supply the engine. The data from a typical test run is shown in Fig. 6.

Several static test runs were performed. The last three runs were used for stand qualification. The data acquired was processed in Matlab and the thrust data was corrected for the ambient pressure using equation (1):

$$
T h r_{-} c=T h r \times 10325 \mathrm{~Pa} / \mathrm{Pamb},
$$

where the $T h r$ is the measured thrust, and the Pamb is the measured ambient pressure. Then a second-degree polynomial was fitted to the data and was compared to the published propeller data (Fig. 7). The similarity achieved is fine. The goodness of fit figures are as follows in Table 2.

Table 2. Goodness of fit of thrust measurement.

\begin{tabular}{|c|c|}
\hline Figure of merit & value \\
\hline Coefficient of determination (R-squared) & 0,98056 \\
\hline Root mean square error (RMSE), N & 3,97 \\
\hline
\end{tabular}

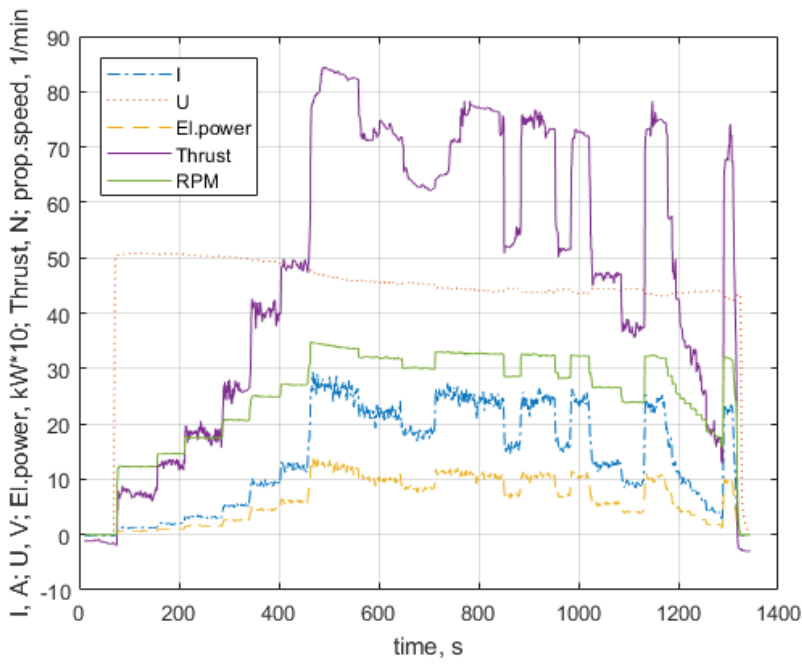

Fig. 6. Typical static test run data plot for $\mathrm{G} 29 \times 9,5$ propeller.

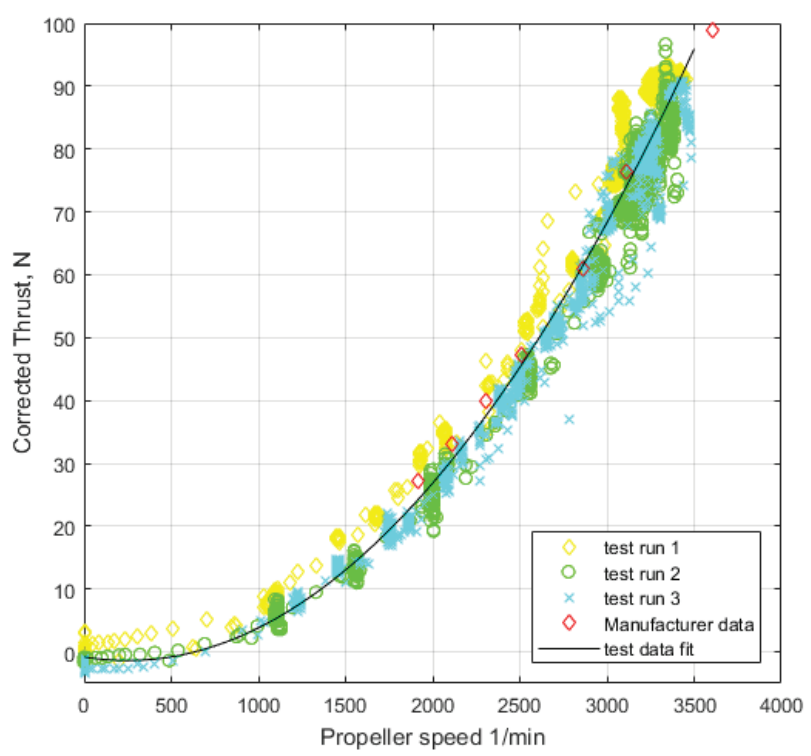

Fig. 7. Comparison of manufacturer and experimental data for T-Motor U11KV90 engine with T-Motor G29×9,5 propeller. 


\section{Runway testing}

The runway tests were performed with Menz-E 26x20 2blade wooden propeller at Sapareva Banya runway (Fig. 5). The duration of the tests was approximately $50 \mathrm{~min}$ and was limited by the endurance of the battery packs used.

The propeller was tested at speeds ranging from 10 to $25 \mathrm{~m} / \mathrm{s}$. As accurate keeping of the airspeed was impossible due to the uneven motion of the automobile and the open-air turbulence, the focus was on postprocessing the acquired data in Matlab. The test data was filtered and only data points with small rate of change of the speed, rpm and thrust readings were picked. The data was then used to estimate the propeller advance ratio and coefficients of thrust and power in accordance with the common formulae for propeller performance, that can be found in the literature, for instance in [7].

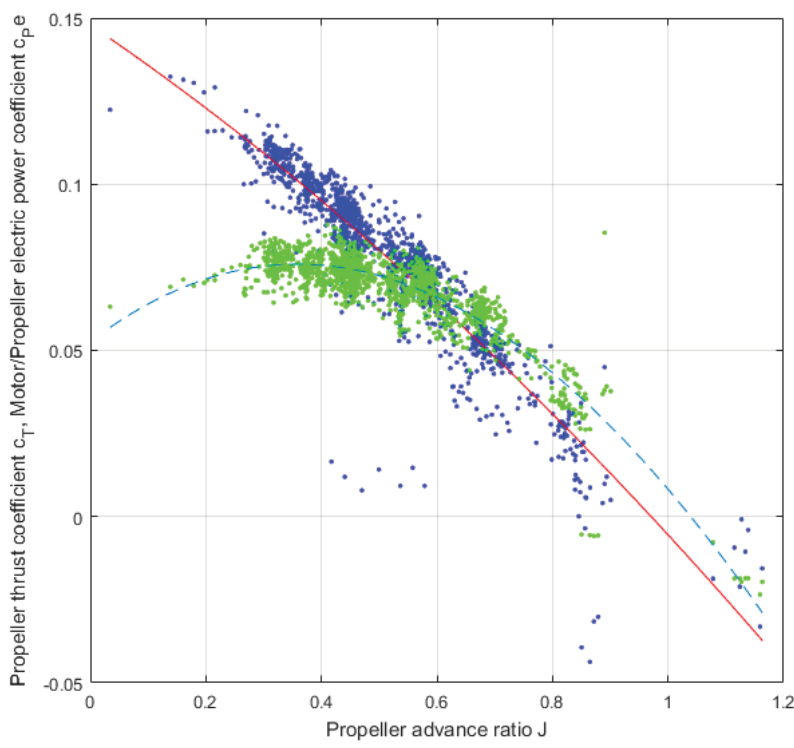

Fig. 8. Estimation of thrust (solid line) and power at electric motor input (dashed line) characteristics for Menz-E $26 \times 20$ propeller.

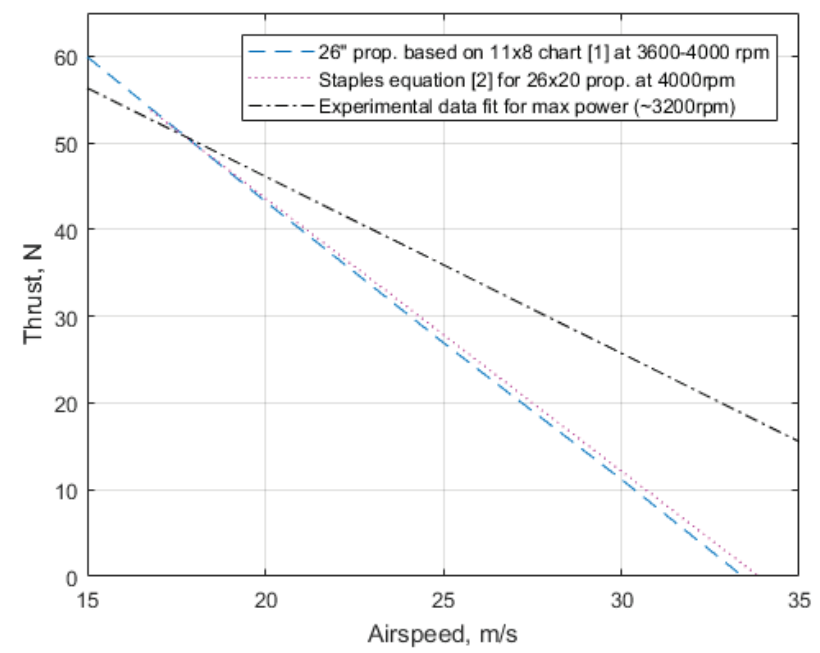

Fig. 9. Thrust comparison between U11KV90 engine with Menz-E26 $\times 20$ propeller and estimates based on [1] and [2].
The results and the fitted curves for the coefficients of thrust $C_{T}$ and power $C_{P}$ are presented in Fig. 8 .

Because experimental data for engine shaft power did not exist, electrical power was used instead. The results are still adequate, since the efficiency of the engine is relatively constant and the shaft power can be estimated through further calculations.

A comparison between the experimental results and the estimates for the $26 \times 20$ propeller thrust, based on [1] and [2] is shown on Fig. 9. It is obvious that the differences are quite significant, which fully justifies the efforts for having the test bench.

\section{Conclusions}

Although aimed at solving practical problems at relatively low cost, the test stand showed a great potential for solving research problems in the field of powerplants for middle sized fixed wing UAVs.

The data collected during the experiments was successfully used for estimation of the powerplant performance characteristics with acceptable accuracy.

The idea of mounting the test bench on the roof of a passenger car was practical and consideration was given to performing the experiments in calm weather conditions.

The experience gained allows for significant improvements in the data acquisition system of the test bench and in the accuracy of the collected data without significant rise in equipment costs.

The authors would like to thank Professor Michael Todorov head of the Department of Aeronautics at Technical University - Sofia for supporting the work on this project.

\section{References}

1. J. Brandt, M. Selig, Propeller Performance Data at Low Reynolds Numbers, AIAA 2011-1255, (2011)

2. G. Staples, Propeller Static \& Dynamic Thrust Calculation,

http://www.electricrcaircraftguy.com/2014/04/propel ler-static-dynamic-thrust-equation-background.html

3. F. Panayotov, I. Dobrev, F. Massouh, M. Todorov, Numerical model for rapid computatuon of the flowfield of a rotor in hover, ICMT 2017, Brno, Czech Republic (2017)

4. H.Panayotov, S. Penchev, Determination of propeller characteristics for multirotor drone design, TECHSYS 2017, Plovdiv, Bulgaria (2017)

5. LEAPTech to Demonstrate Electric Propulsion Technologies https://www.nasa.gov/centers/ armstrong/Features/leaptech.html (2015)

6. T-Motor U11 KV90 electric motor specifications: http://store-en.tmotor.com/goods.php?id=328

7. E.Torenbeek, Synthesis of Subsonic Aircraft Design, Delft Univerity Press, Delft, The Netherlands, 191, (1982) 